\title{
IMPLEMENTATION OF NON DESTRUCTIVE COMBINED TEST METHODS IN PREDICTION OF CONCRETE STRENGTH IN EGYPT
}

\author{
1- Mariam farouk ghazy ${ }^{*}$ 2- Metwally abd allah abd elaty ${ }^{*}$ \\ * Faculty of engineering, Structural engineering department, Tanta University, Egypt \\ 1-Email:dr.mariamghazi@yahoo.com \& 2-Email: drmet2828@yahoo.com
}

\begin{abstract}
Experimental investigations to study the efficiency of using single non destructive test and combined methods to predict the concrete compressive strength have been conducted. Different concrete mixes including different types of coarse aggregates and mix proportions are considered. Concrete age's ranges from one to sixty days were covered. The statistical analysis of the results reveals that; with a reasonable correlation coefficient, rebound hammer and ultrasonic pulse velocity tests could be implemented individually to measure the compressive strength of concrete at age rang from one to sixty days. Moreover, the use of both the rebound hammer and the ultrasonic pulse velocity tests as a combined method produces more reliable results that are closer to the actual compressive values compared to the use of one of the implemented methods individually. A proposed equation combines both rebound hammer and ultrasonic pulse velocity tests could be implemented securely for in situ concrete strength assessment has been established

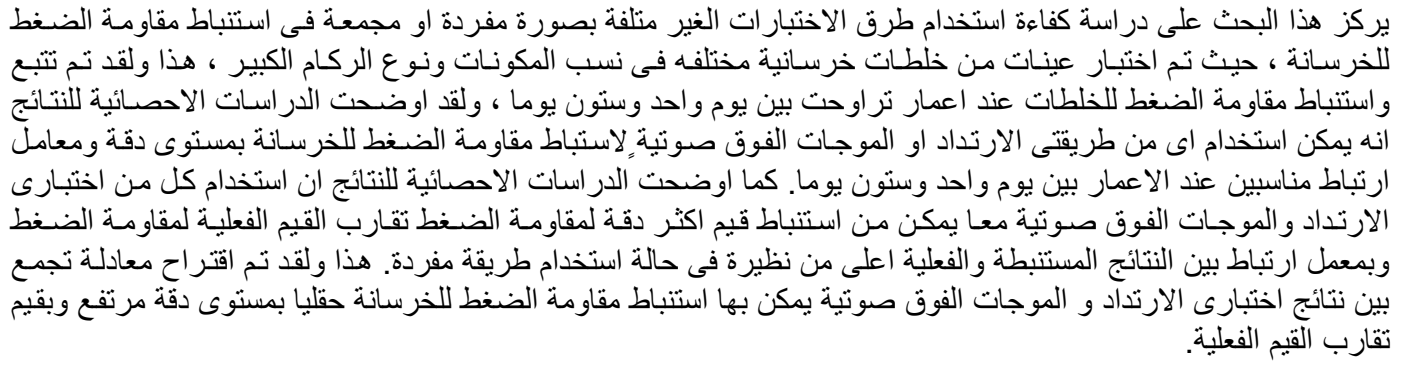

Keywords: Assessment; In situ concrete; Rebound number; Ultrasonic pulse velocity; combined tests; Compressive strength.

\section{INTRODUCTION}

Non-destructive testing (NDT), which estimates the strength of concrete without destroying the structure is widely used. That method has been used successfully to measure either the strength property of concrete or a physical or mechanical property, which can be correlated to strength [1].

Non-destructive testing could be applied to both of old and new structures. For new structures, the principal applications are likely to be for quality control or the resolution of doubts about the quality of materials used in construction. Testing of existing structures is usually related to an assessment of structural integrity or adequacy. In either case, if destructive testing alone is used, for instance, by removing cores for compression testing, the cost of coring and testing may only allow relatively a small number of tests to be carried out on a large structure, which may be misleading. Non-destructive testing could be used in such those situations as a preliminary to subsequent coring [2].

In essence, the objective of in-place testing is to estimate the compressive strength of concrete in the structure. Estimation of in situ strength requires a previous known relationship between the result of the in-place test and the strength of the concrete. For new constructions, the relationship is usually established empirically in the laboratory. Whereas, for exist constructions, the relationship is usually established by 


\section{Mariam F. Ghazy and Metwally A. Abd Elaty, "Implementation Of Non Destructive Combined ..."}

performing in-place tests at selected locations in the structure and determining the strength of cores drilled from adjacent locations [3].

Nondestructive test methods are applied to concrete structures to achieve four primary reasons [4]:

- Quality control of new construction;

- Troubleshooting of problems with new construction;

- Condition evaluation of older concrete for rehabilitation purposes; and

- Quality assurance of concrete repairs.

Currently, in Egypt the use of non-destructive testing NDT has become significant and wide for guidance on the level of quality control of in situ concrete or /and to determine the validity of the building by deducing its compressive strength from rebound hammer RH curves or catalogue.

Many research works have concluded several simple equations that correlate between concrete compressive strength $\mathrm{Fc}$ and ultrasonic pulse velocity $\mathrm{V}$. Moreover, multi equations can correlate concrete compressive strength with both rebound number $\mathrm{R}$ and pulse velocity $\mathrm{V}$ have been concluded by researchers. Despite of all these and the widely use of ultrasonic pulse velocity in situ, no recommended equations are given in codes of practice can correlate between compressive strength Fc and pulse velocity $\mathrm{V}$.

Some of the pioneering works in this field, carried out in the 1950s and 1960s, were reported [5-7]. Establishment of a series of specific correlations between the combination of rebound hammer number $\mathrm{R}$ and ultrasonic pulse velocity $\mathrm{V}$ and the compressive strength Fc of concretes, each containing a particular aggregate type and being of a particular age mix, was completed in the early 1970s [8].

As a result, over a wide range of maturity, the relationship between compressive strength and pulse velocity is highly nonlinear. Figure 1 shows a typical relationship between compressive strength and pulse velocity $\mathrm{V}$. That figure is only an illustrative example and the actual relationship depends on the specific concrete mixture. At early maturities, a given increase in compressive strength results in a relatively large increase in pulse velocity, while at later ones the velocity increase is smaller for the same strength increase. Combined methods are reported to increase the reliability of the estimated strength. The underlying concept is that if the two methods are influenced in different ways by the same factor, their combined use results in a canceling effect that improves the accuracy of the estimated strength. For example, an increase in moisture content increases $\mathrm{V}$ but decreases $\mathrm{R}$ [3]. Relatively higher correlation coefficients for the estimated strength are recorded using the combined methods for NDT tests compared to those estimated using individual methods.

Several previous studies [9-13], concluded that there is a good correlation between $\mathrm{V}, \mathrm{R}$ or both and the compressive strength as a single-variable equations (Eqs. 1 to 6) or multi-variable equations (Eqs. 7 to 9) as given in Table 1.

Table 1: Equations of previous studies used for estimation compressive strength of concrete

\begin{tabular}{|c|c|c|c|c|}
\hline $\begin{array}{c}\text { References } \\
\text { No. }\end{array}$ & Equations & Units & $\begin{array}{l}\text { Eq. } \\
\text { No. }\end{array}$ & $\mathrm{RMSE}^{*}[14]$ \\
\hline \multicolumn{5}{|c|}{ Single-variable equations } \\
\hline Kheder, G. F. [11] & $\begin{array}{c}F c=1.2 \times 10^{-5} \mathrm{xV}^{1.7447} \\
F c=0.403 \mathrm{xR}^{1.2063}\end{array}$ & $\begin{array}{c}\mathrm{Fc}(\mathrm{MPa}) \\
\mathrm{V}(\mathrm{m} / \mathrm{s})\end{array}$ & $\begin{array}{l}1 \\
2\end{array}$ & $\begin{array}{l}6.0974 \\
2.1651\end{array}$ \\
\hline Qasrawi, Y. H. [12] & $\begin{array}{l}F c=36.72 \mathrm{xV}-129.077 \\
F_{c}=1.353 \times R-17.393\end{array}$ & $\begin{array}{l}\mathrm{Fc}(\mathrm{MPa}) \\
\mathrm{V}(\mathrm{km} / \mathrm{s})\end{array}$ & $\begin{array}{l}3 \\
4\end{array}$ & $\begin{array}{l}3.6981 \\
2.8152\end{array}$ \\
\hline $\begin{array}{c}\text { Shariati, M., et al. } \\
\text { [13] }\end{array}$ & $\begin{array}{l}F_{C}=15.533 x V-34.358 \\
F c=1.7206 x R-26.595\end{array}$ & $\begin{array}{l}\mathrm{Fc}(\mathrm{MPa}) \\
\mathrm{V}(\mathrm{km} / \mathrm{s})\end{array}$ & $\begin{array}{l}5 \\
6\end{array}$ & $\begin{array}{l}3.3746 \\
2.1024\end{array}$ \\
\hline \multicolumn{5}{|c|}{ Multi-variable equations } \\
\hline Meynik et al. [9] & $F c=-24.668+1.427 x R+0.0294 x^{4}$ & $\begin{array}{l}\text { Fc(MPa), } \\
\mathrm{V}(\mathrm{km} / \mathrm{s})\end{array}$ & 7 & 7.0654 \\
\hline Tanigawa Y. [10] & $F_{c}=0.745 \times R+0.951 \times V-0.544$ & $\begin{array}{l}\mathrm{Fc}(\mathrm{MPa}) \\
\mathrm{V}(\mathrm{km} / \mathrm{s})\end{array}$ & 8 & 2.1 \\
\hline Kheder, G. F. [11] & $F_{c}=0.0158 \mathrm{xV}^{0.4254} \mathrm{xR}^{1.1171}$ & $\begin{array}{l}\mathrm{Fc}(\mathrm{MPa}) \\
\mathrm{V}(\mathrm{km} / \mathrm{s})\end{array}$ & 9 & 2.1375 \\
\hline
\end{tabular}

\footnotetext{
- Root mean square error.

$R M S E=\sqrt{\frac{1}{n} \sum_{1}^{n}\left(f_{c_{c o}}-f_{c_{-m}}\right)^{2}}$
} 


\section{Mariam F. Ghazy and Metwally A. Abd Elaty, "Implementation Of Non Destructive Combined ..."}

The development of the non-destructive determination of concrete strength using 200 concrete core specimens taken from randomly chosen columns and shear walls of various reinforced concrete structures in Istanbul and Izmit, Turkey since 2000 was studied [1].

In the non-distractive methods of testing, the specimens were not loaded to failure and as such the strength inferred or estimated cannot be expected to yield absolute values of strength. Those methods, therefore, attempt to measure some other properties of concrete from which compressive strength could be predicted. Among the available NDT methods, rebound hammer RH method provides an inexpensive, simple and quick method for obtaining an indication of concrete strength. The ultrasonic pulse velocity UPV method is an ideal tool for establishing whether concrete strength is uniform or not. It could be used for both existing structures and those under construction.

Moreover, other methods tend to be more time consuming and expensive to use than the $\mathrm{RH}$ and UPV methods [15].

The main objective of this study is to establish a correlation between the compressive strengths measured by compression tests and both of RH and UPV tests as non-destructive test methods NDT. The combination of both RH and UPV methods are the most commonly used. In the majority of cases, the need for in situ concrete strength evaluation arises as a result of suspect of concrete quality.

So, this study is amid at implementation of non destructive combined test methods to estimate the in situ concrete compressive strength at different ages.

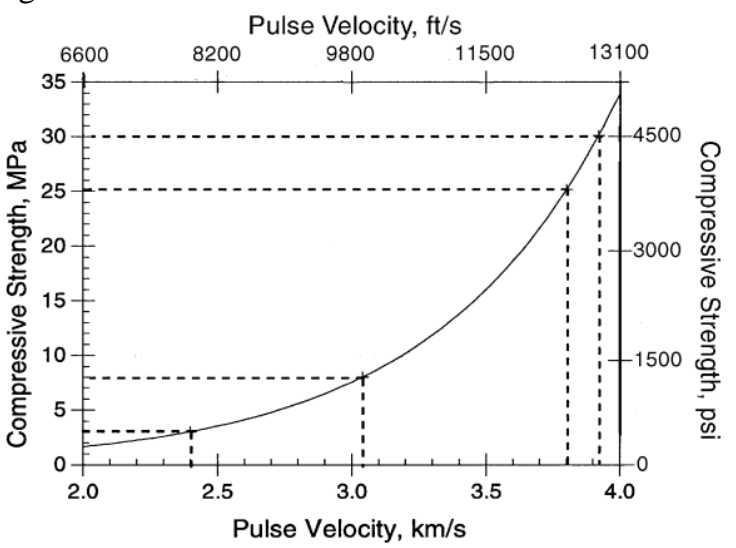

Fig. 1: Schematic of typical relationship between pulse velocity and compressive strength of a given concrete mixture

\section{Experimental Program}

The present experimental program is designed to investigate the concrete compressive strength by applying both of RH and UPV tests of previously prepared concrete samples. Furthermore, the actual compressive strength values are measured by performing compressive strength tests on the previously investigated samples. Age of specimens, aggregate type, cement content and mix proportions are being the main investigated parameters. Table 2 presents the schedule of the experimental program.

Table 2: Experimental program

\begin{tabular}{|c|c|c|c|c|}
\hline \multirow{2}{*}{$\begin{array}{l}\text { Mix } \\
\text { no. }\end{array}$} & \multirow{2}{*}{$\begin{array}{c}\text { Aggregate } \\
\text { type }\end{array}$} & \multirow{2}{*}{$\begin{array}{c}\text { Cement content, } \\
\mathrm{kg} / \mathrm{m}^{3}\end{array}$} & \multicolumn{2}{|c|}{ Tests properties } \\
\hline & & & Fresh & Hardened \\
\hline 1 & Gravel & 350 & \multirow{4}{*}{$\begin{array}{c}\text { - Slump } \\
\text { - Compacting } \\
\text { factor }\end{array}$} & \multirow{4}{*}{$\begin{array}{l}\text { - Compressive strength of } \\
\text { cubes (150x150x } 150 \mathrm{~mm}) \\
\text { At } 1,3,7,28,60 \text { days } \\
\text { - Rebound hammer } \\
\text { At } 3,7,28,60 \text { days } \\
\text { - Ultrasonic pulse velocity } \\
\text { At } 3,7,28,60 \text { days }\end{array}$} \\
\hline 2 & Dolomite & 350 & & \\
\hline 3 & Gravel & 450 & & \\
\hline 4 & Dolomite & 450 & & \\
\hline
\end{tabular}

\subsection{Materials and procedure}

The constituent of materials used in this study were locally available materials in Egypt and specified by the following:

1- Cement: Ordinary Portland cement of grade $42.5 \mathrm{~N}$ was used in this investigation. The used Cement is confirmed to the Egyptian Standard Specifications ES requirements (4756-1/2005).

2- Fine aggregates: Medium well-graded sand of fineness modulus 2.2 was used.

3- Coarse aggregates: Natural well-graded gravel aggregate of $37.5 \mathrm{~mm}$ maximum nominal size was used. It included a combination of round and angular particles. The surface of the particles was more or less smooth and regular. Natural crushed lime stone or dolomite aggregate of $37.5 \mathrm{~mm}$ nominal size as given by quarries was also used in this investigation. The dolomite was obtained from Attaka quarries its particles have a granular porous texture, rough surface and irregular. Fine and coarse aggregates confirmed the Egyptian standard specifications ES requirements (1109-2002) were used. Figure 2 shows the grading curves of the used aggregates. The percentage passing of sieve $9.5 \mathrm{~mm}$ for gravel aggregate is somewhat lower compared to the lower limit of ES. That trend was noticed for the gravel used in this work. In contrary, a remarkable increase of the percentage passing of the used dolomite from sieve of $9.5 \mathrm{~mm}$ opening size was recorded. Furthermore, the aggregate is usually used as a combined aggregate, in which 


\section{Mariam F. Ghazy and Metwally A. Abd Elaty, "Implementation Of Non Destructive Combined ..."}

combinations of coarse and fine aggregates are suitably proportioned. In fact, used combined aggregate was well comply with ES requirements and the grading curve is located between the lower and upper limits of grading stated in ES. So the results could be considered comparable based on grading of combined aggregate not based on grading of coarse aggregate.

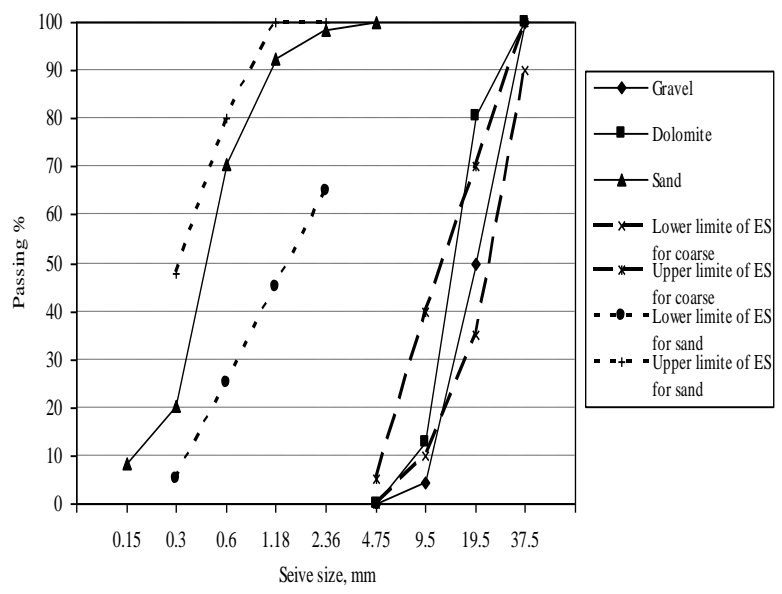

Fig. 2: Grading of used aggregates

Four concrete mixes were investigated. The proportions of mixes are given in Table 3 . Immediately, after complete mixing of the constituent, slump test and compacting factor test in accordance to Egyptian code of practice ECP 2032007 [16] and British standard specifications BS 1881 part 103 [17] were conducted to measure the fresh properties for each mix and the results are given in Table 3 .

Standard cubes $(150 \times 150 \times 150 \mathrm{~mm})$ of concrete mix were prepared to measure compressive strength conforming to ECP 203-2007 [16] and BS 1881 part 108 and part $115[18,19]$. The cubes were removed from moulds after 24 hours of casting. The hardened concrete specimens were continuously stored in water $\left(20 \pm 2{ }^{\circ} \mathrm{C}\right)$ until the age of testing. A total of 100 concrete cubes were investigated for the four studied concrete mixes. For each mix, twenty-five concrete cubes were studied at five different ages namely, 1, 3, 7, 28 and 60 days. For each age, five cubes were inspected by both of RH and UPV tests then; finally a crushing test was preformed.
Table 3: Concrete mixes proportions

\begin{tabular}{|c|c|c|c|c|c|c|c|}
\hline Mix no. & $\begin{array}{l}\text { Cement, } \\
\mathrm{kg}^{3} \mathrm{~m}^{3}\end{array}$ & $\begin{array}{c}\text { Coarse } \\
\text { aggregate, } \\
\mathrm{kg} / \mathrm{m}^{3}\end{array}$ & $\begin{array}{l}\text { Sand, } \\
\operatorname{lgg} \mathrm{m}^{3}\end{array}$ & $\begin{array}{l}\text { Water, } \\
\operatorname{kg} \mathrm{m}^{3}\end{array}$ & $\begin{array}{l}w / C \\
\text { ratio }\end{array}$ & $\begin{array}{l}\text { Slump } \\
\text { m }\end{array}$ & $\begin{array}{c}\text { Compacting } \\
\text { factor }\end{array}$ \\
\hline 1 (gravel) & 350 & 1268 & 634 & 157.5 & 0.45 & 100 & 0.96 \\
\hline 2(dolomite) & 350 & 1247 & 623 & 169.75 & 0.485 & 80 & 0.95 \\
\hline 3 (gravel) & 450 & 1135 & 567 & 202.5 & 0.45 & 125 & 0.97 \\
\hline 4 (dolomite) & 450 & 1107 & 553 & 218.25 & 0.485 & 105 & 0.967 \\
\hline
\end{tabular}

The ultrasonic pulse velocity test UPV has been carried out conforming to $[3,4]$ using the portable digital indicating tester known as PUNDIT. Direct transmission measurements on cubes were implemented. The pulse velocity $\mathrm{V}$ was measured for the five tested cubes and the average was considered in the next regression analysis.

For UPV test it is important to maintain good acoustical contact between the surface of concrete and the face of each transducer. Moreover, smoothen of the surface is desirable by the use of a carborundum stone and the transducers should be held tightly against the concrete surface. In addition, the use of a coupling medium was essential to confirm wave transmission.

At laboratory, access to apposite surfaces is generally available, which enables applying direct transmission procedure for UPV test. Whereas, at field, access to opposite surfaces of a component may not be readily available and tests may need to be conducted as indirect transmission procedure [20].

Temperatures between $5{ }^{\circ} \mathrm{C}$ and $30{ }^{\circ} \mathrm{C}$ don't significant affect the $\mathrm{V}$ measurements in concrete. At temperatures between $30{ }^{\circ} \mathrm{C}$ and $60{ }^{\circ} \mathrm{C}$, there is up to $5 \%$ reduction in pulse velocity. Below $0{ }^{\circ} \mathrm{C}$ the measured velocity values tend to increase.

Schmidt rebound hammer test $\mathrm{RH}$ conforming to ACI [3,4] using type $N$ Schmidt hammer was implemented in this study. For RH, smoothness under test is considered as affecting the results of $\mathrm{R}$. Using a carborundum stone for smoothness of surface before test is essential.

In order to perform the RH test on cubes, it is necessary to ensure that the cubes are restrained from moving; else, the reading will not be accurate. Hence cubes were restrained by applying a small force using the hydraulic compression testing machine prior to testing. Twenty readings of $\mathrm{R}$ at least for each cube in horizontal direction (10 readings for each face as one set) were taken in a predetermine intersection on two faces as a two 
sets. The results of the $\mathrm{R}$ were statistically analyzed to get the average for each cube. The average of the five tested cubes was considered to get the alternative compressive strength.

Compression test was carried out for the hardened concrete cubes using a hydraulic compression testing machine with total capacity of $1500 \mathrm{kN}$.

\section{Results and Discussions}

An experimental investigation, aims at evaluation of using both of RH and UPV methods, to estimate the concrete compressive strength was carried out. Four concrete mixes include two types of coarse aggregates have been investigated. NDT including RH and UPV tests to evaluate concrete compressive strength and quality process at different ages have been carried out. Test results of the experimental program are presented in Table 4. A statistical analysis using Microsoft excel software for the experimental data has been performed. The following paragraphs illustrate the experimental results.

Table 4: Test results for different mixes

\begin{tabular}{|c|c|c|c|c|c|}
\hline $\begin{array}{c}\text { Mix } \\
\text { no. }\end{array}$ & $\begin{array}{l}\text { Concrete } \\
\text { age, day }\end{array}$ & $\begin{array}{l}\text { Average* } \\
\text { rebound } \\
\text { number }\end{array}$ & $\begin{array}{l}\text { Compressive } \\
\text { strength } \\
\text { from } \\
\text { rebound } \\
\text { number, } \\
\mathrm{MPa}\end{array}$ & $\begin{array}{l}\text { Average }^{*} \\
\text { compressive } \\
\text { strength of } \\
\text { cubes, MPa }\end{array}$ & $\begin{array}{l}\text { Ultrasonic }^{*} \\
\text { pulse } \\
\text { velocity, } \\
\mathrm{km} / \mathrm{s}\end{array}$ \\
\hline \multirow{5}{*}{1} & 1 & - & - & 10.7 & - \\
\hline & 3 & 23.3 & 11.5 & 14.7 & 4 \\
\hline & 7 & 27.2 & 17.2 & 17.4 & 4.1 \\
\hline & 28 & 33 & 27.1 & 28.4 & 4.4 \\
\hline & 60 & 35.5 & 30 & 31.4 & 4.4 \\
\hline \multirow{5}{*}{2} & 1 & - & - & 12.9 & - \\
\hline & 3 & 24.4 & 14.7 & 16.5 & 4.1 \\
\hline & 7 & 28 & 18.5 & 19.4 & 4.2 \\
\hline & 28 & 33.5 & 29 & 31.6 & 4.4 \\
\hline & 60 & 35.7 & 31.5 & 33.1 & 4.5 \\
\hline \multirow{5}{*}{3} & 1 & - & - & 15.2 & - \\
\hline & 3 & 27.9 & 19.4 & 20.5 & 4.2 \\
\hline & 7 & 30.9 & 20.9 & 24.8 & 4.3 \\
\hline & 28 & 34.4 & 33.5 & 40.9 & 4.6 \\
\hline & 60 & 38.8 & 40.5 & 43.2 & 4.6 \\
\hline \multirow{5}{*}{4} & 1 & - & - & 18.1 & - \\
\hline & 3 & 28.9 & 18 & 22.2 & 4.2 \\
\hline & 7 & 31.8 & 22 & 27.1 & 4.3 \\
\hline & 28 & 35.5 & 35 & 43.5 & 4.6 \\
\hline & 60 & 40 & 42.5 & 45.5 & 4.6 \\
\hline
\end{tabular}

* Average of five cubes

\subsection{Results of rebound hammer RH and ultrasonic pulse velocity UPV}

Figure 3 presents the relationship between the rebound number $\mathrm{R}$ and the corresponding compressive strength from crushing test. The results of the four tested mixes are included. For each mix, the developments of the compressive strength with age have been recorded. For each concrete mix, second degree regression equation with high correlation coefficient representing the relation between $\mathrm{R}$ and the crushing strength could be proposed as;

$$
\mathrm{F}_{\mathrm{c}}=\mathrm{A} \mathrm{R}^{2}+\mathrm{B} \mathrm{R}+\mathrm{C} \quad \text { where; }
$$

$\mathrm{F}_{\mathrm{c}}$ is the compressive strength, $\mathrm{R}$ is the rebound number and $\mathrm{A}, \mathrm{B}$ and $\mathrm{C}$ are constants

Figure 4 presents the relationship between $\mathrm{V}$ results and the corresponding compressive strength from crushing test. The results of the four tested mixes are included. For each mix, the developments of the compressive strength with age have been recorded. For each concrete mix, linear regression equation with high correlation coefficient representing the relation between $\mathrm{V}$ and the crushing strength could be proposed as;

$$
\mathrm{F}_{\mathrm{c}}=\mathrm{D} \mathrm{V}+\mathrm{E} \quad \text { where; }
$$

$F_{c}$ is the compressive strength, $\mathrm{V}$ is the pulse velocity and $\mathrm{D}$ and $\mathrm{E}$ are constants

The relationship between the values of the $R$ and the corresponding crushing strength for all the tested specimens are presented in Fig. 5. An exponential regression equation Eq. 10, relates $\mathrm{R}$ and the compressive strength, is proposed with a correlation coefficient $\mathrm{R}^{2}=0.9307$.

$$
\mathrm{F}_{\mathrm{c}}=2.6819 \mathrm{e}^{0.0726 \mathrm{R}}
$$

Where, $F_{c}(\mathrm{MPa})$ is the compressive strength and $\mathrm{R}$ is the rebound number. 


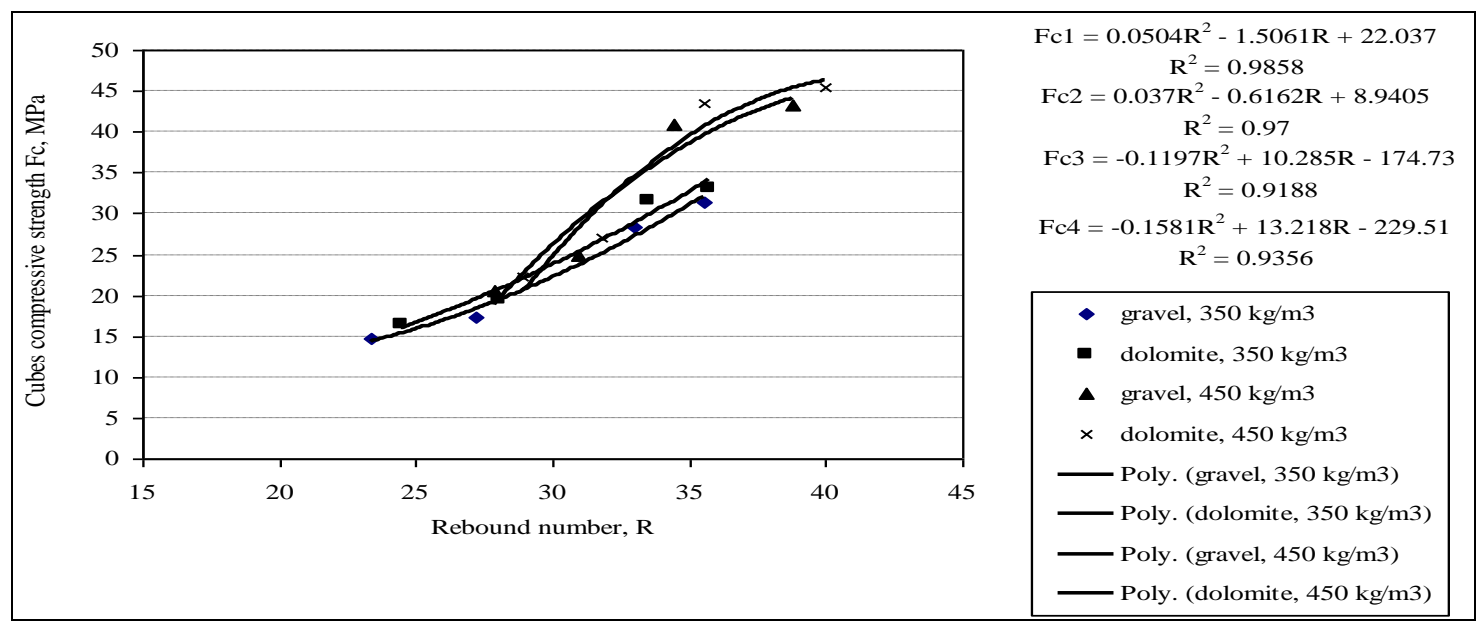

Fig. 3: Relationship between $R$ and compressive strength of standard cubes

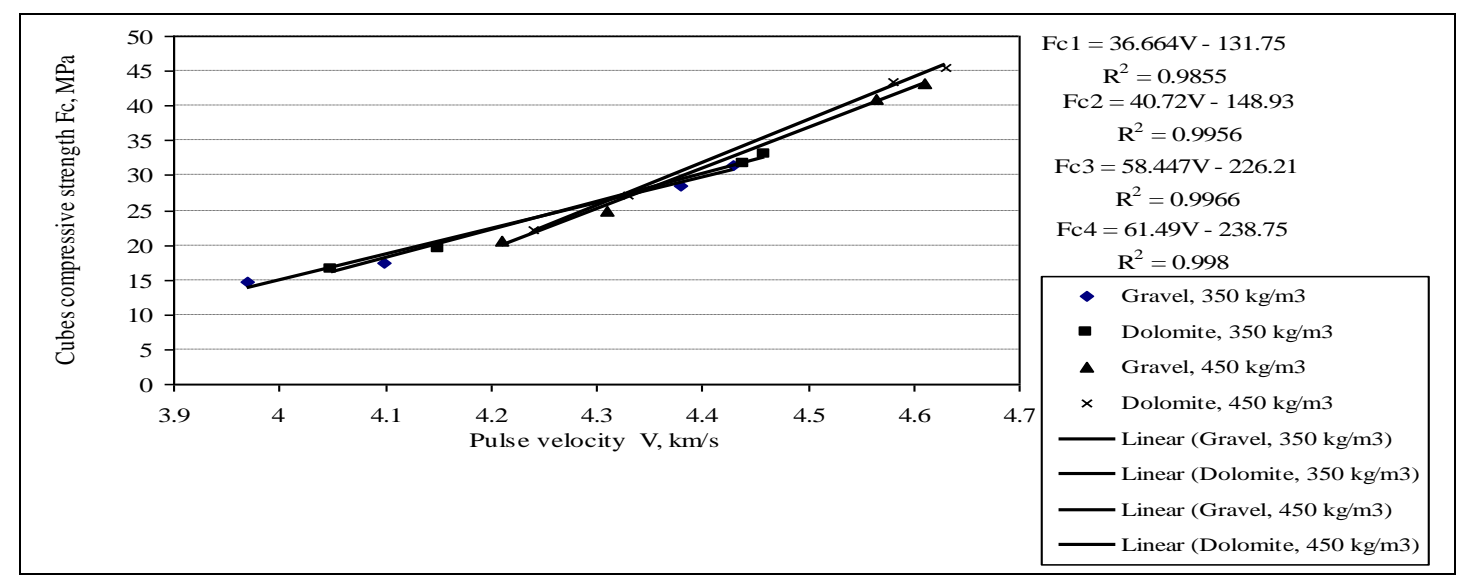

Fig. 4: Relationship between $V$ and compressive strength of standard cubes

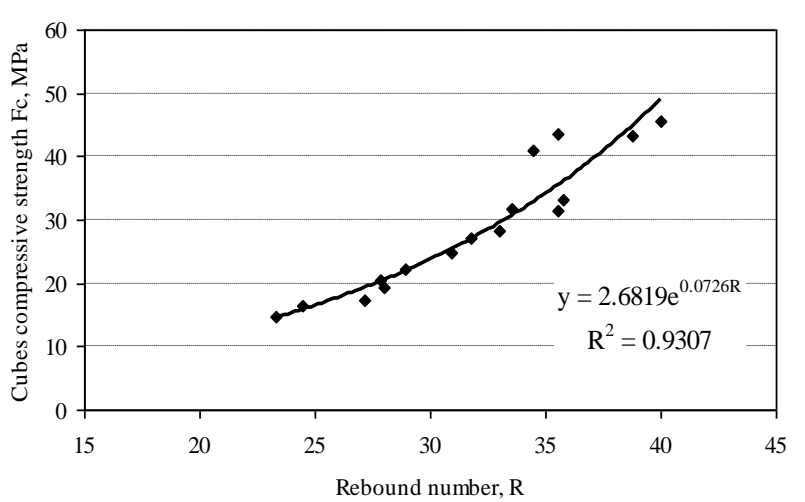

Fig. 5: Relationship between $R$ and compressive strength of standard cubes
The relationship between the values of $\mathrm{V}$ and the corresponding crushing strength for all the tested specimens are presented in Fig. 6. An exponential regression equation Eq. 11, relates $\mathrm{V}$ and the compressive strength, is proposed with a correlation coefficient $R^{2}=0.9946$.

$$
\mathrm{F}_{\mathrm{c}}=0.0125 \mathrm{e}^{1.7695 \mathrm{~V}}
$$

Where, $\mathrm{F}_{\mathrm{c}}(\mathrm{MPa})$ is the compressive strength and $\mathrm{V}$ $(\mathrm{km} / \mathrm{s})$ is the pulse velocity.

Equations 10 and 11 present single variable equations with significant correlation coefficients since $\mathrm{R}^{2}$ values are found to be 0.9307 and 0.9946 which indicates a significant correlation for $\mathrm{R}$ and $\mathrm{V}$, respectively. 


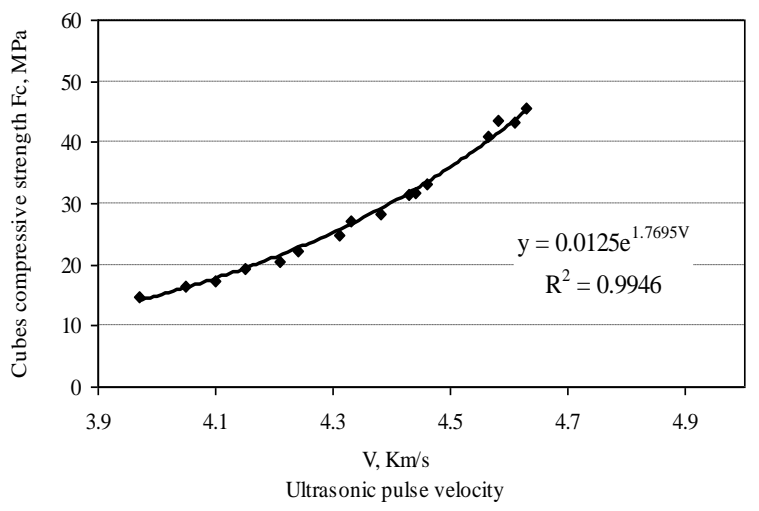

Fig. 6: Relationship between $\mathrm{V}$ and compressive strength of standard cubes

To compare the efficiency of the present proposed equation (Eq. 10) in prediction the compressive strength with the previously proposed equations by researches [11-13], the results are scattered in Fig. 7. In contrary of the previous investigations, not only the late age results are considered but also the early age properties are included in this curve. In addition to the early age results different coarse aggregate types are also considered. As concrete at 1 day age doesn't have enough surface hardness which may cause the damage of the concrete surface if it is tested by RH, due to that the data for NDT at 1 day are not gathered. This figure shows a good agreement between the present proposed equation (Eq. 10) and the previously proposed equations by authors.

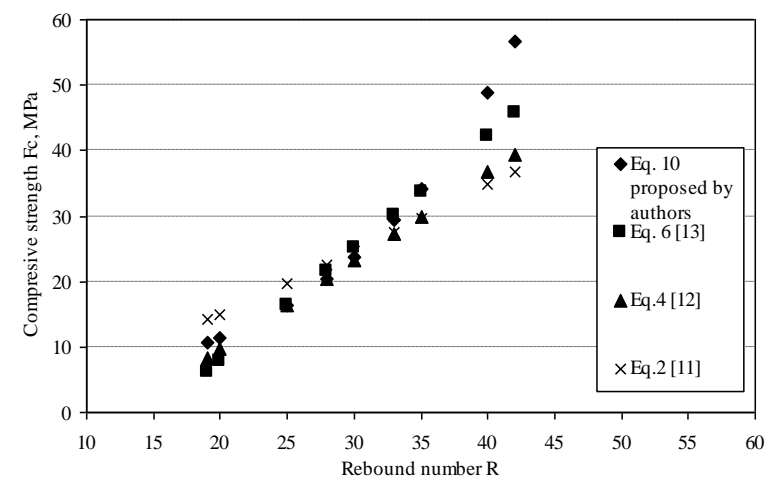

Fig. 7: Comparison between predicted compressive strength and $\mathrm{R}$

Figure 8 shows the comparison between the predicted compressive strength and $\mathrm{V}$ (calculated by Eq. 11 proposed by authors). It could be noticed that below $\mathrm{V}$ of $4 \mathrm{~km} / \mathrm{s}$, there are a noticeable agreement between the predicted values from the present proposed equation (Eq. 11) and those predicted by equation 3 . Whereas, equations 1 and 5 are over predict the compressive strength compared to Eqs. 3 and 11. However, above V of 4 $\mathrm{km} / \mathrm{s}$, it could be noticed that the results predicted by the four equations are in good agreement. The effect of different features such as the proportions and type of aggregate, water/cement ratio, curing could be the cause of this difference and it does not mean less confident of this method and/or for the reason of date of testing.

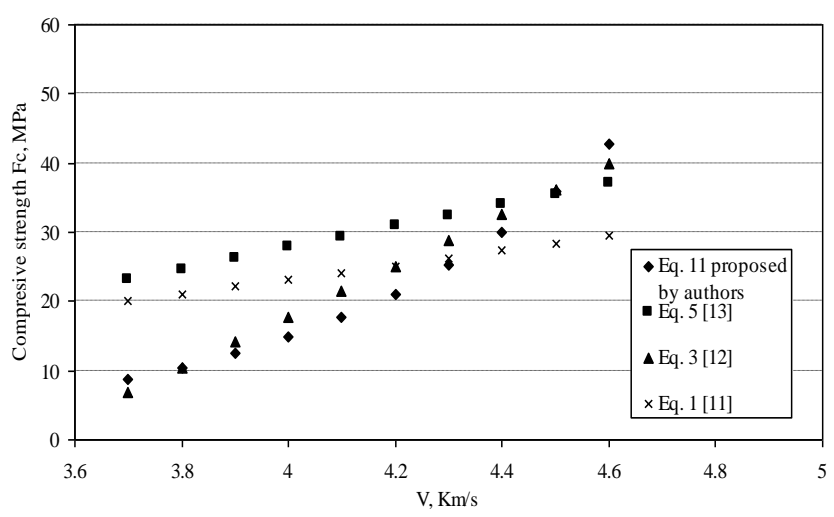

Ultrasonic pulse velocity

Fig. 8: Comparison between predicted compressive strength and $\mathrm{V}$

\subsection{Analysis of test results as combined test methods}

Using NDT to predict the in situ compressive strength is wide spread. Implementation of one method to predict the in situ compressive strength individually may cause, in some cases or some times, confusing to the predicted values. So combination of more than one method as integral tools to predict the compressive strength values may be a useful tool to eliminate the expected error in the predicted property under consideration. Considering that issue and by taking into consideration the results of both R and V, Eq. 12 is proposed. In view of the actual compressive strength and the corresponding predicted values of compressive strength based on the proposed equation (Eq. 12), the results are presented in Fig. 9.

$$
F_{c}=1.341 \mathrm{e}^{0.0726 \mathrm{R}}+0.00625 \mathrm{e}^{1.7695 \mathrm{~V}}
$$

Where, $F_{c}(\mathrm{MPa})$ is the compressive strength, $\mathrm{R}$ is the rebound number and $\mathrm{V}(\mathrm{km} / \mathrm{s})$ is the pulse velocity.

A good agreement is clear between the experimentally measured compressive strength values against the corresponding predicted values according to Eq. 12. 


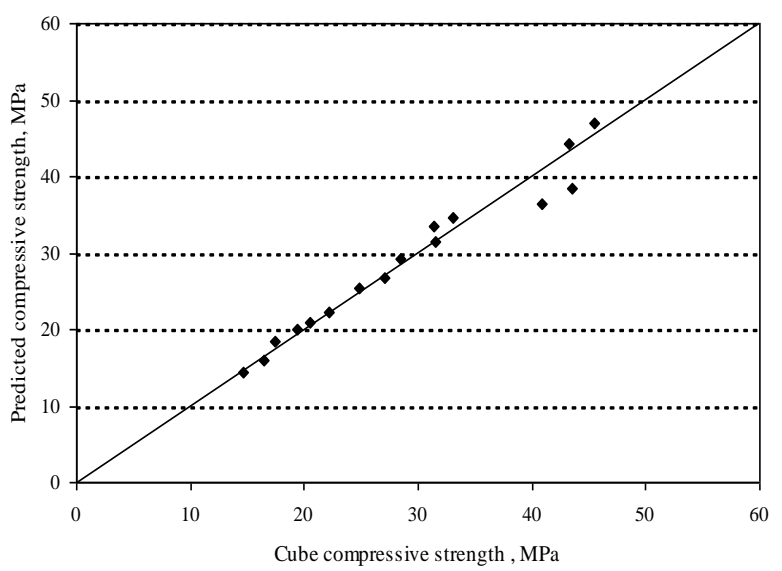

Fig. 9: Comparison between cubes compressive strength and predicted compressive strength using equation 12

To compare the present proposed equation (Eq. 12) with the previously proposed ones, Fig. 10 is constructed. In that figure, the experimentally measured values of the compressive strength versus the predicted ones by both the present formula and those listed in literature are plotted. Equation 12 gives the heights correlation coefficient $\mathrm{R}^{2}=0.9624$. Whereas, Eqs. 7, 8 and 9 show a good correlation coefficient but somewhat less compared to the present proposed equation.

Consequently, the results showed a significant correlation between compression strengths. The use of combined test methods produces more reliable results that are closer to the actual values when compared to the use of one of the NDT methods individually. An acceptable level of precision was additionally appreciated for concrete strength estimation. Therefore, the resulting equations for strength prediction could be used securely for in situ concrete strength assessment.

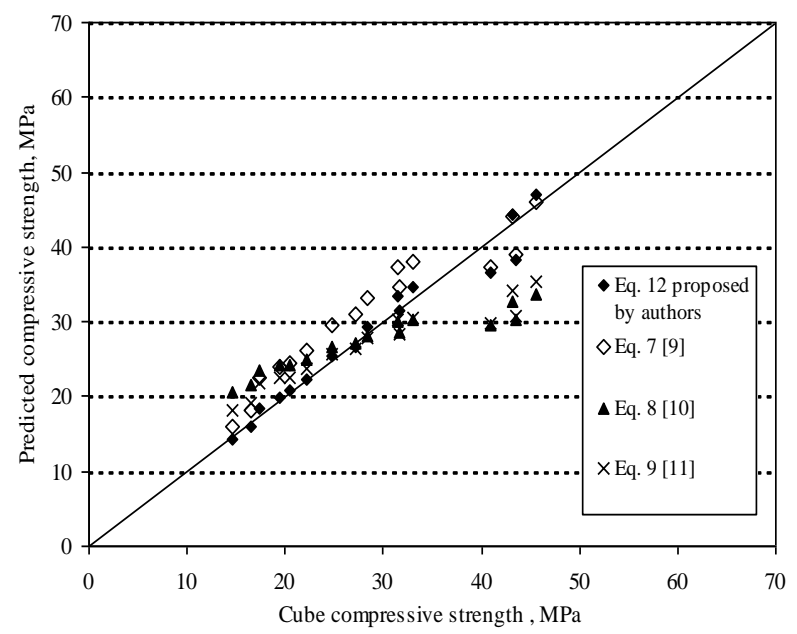

Fig. 10: Comparison of previous equations and equation 12 proposed by authors

\subsection{Concrete age and development of compressive strength}

Figure 11 and Table 5 give a relationship between the concrete ages and the compressive strength. A useful equation with a correlation coefficient $R^{2}=$ 0.9928 represents the relationship between the strength ratios as a percentage of the 28 days compressive strength versus age is proposed as following;

$$
Y=-0.0003 X^{2}+0.0312 X+0.3972 \text { Eq. } 13
$$

Where; $\mathrm{Y}=$ Compressive strength of concrete at the age of test / compressive strength at 28 days age and $\mathrm{X}=$ concrete age days.

Table 5: Effect of age on compressive strength of cubes

\begin{tabular}{|c|c|c|c|c|c|}
\hline \multirow{2}{*}{$\begin{array}{c}\text { Mix } \\
\text { no. }\end{array}$} & \multicolumn{6}{|c|}{$\begin{array}{c}\text { Ratio of 28 days strength }=\text { (compressive } \\
\text { strength at various ages)/ (compressive strength } \\
\text { at 28 days) }\end{array}$} \\
\cline { 2 - 6 } & 1 & 3 & 7 & 28 & 60 \\
\hline 1 & 0.38 & 0.51 & 0.613 & 1 & 1.1 \\
\hline 2 & 0.41 & 0.52 & 0.614 & 1 & 1.05 \\
\hline 3 & 0.38 & 0.5 & 0.609 & 1 & 1.06 \\
\hline 4 & 0.42 & 0.51 & 0.623 & 1 & 1.05 \\
\hline
\end{tabular}

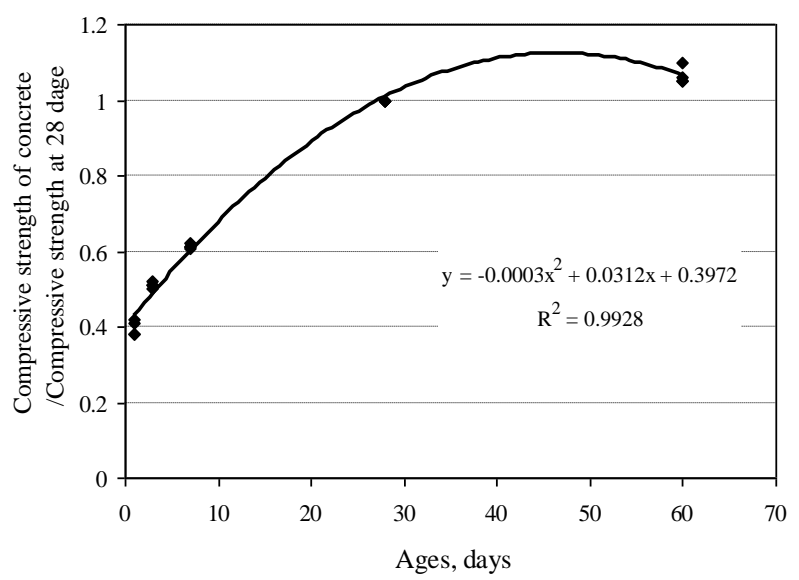

Fig. 11: Correction factor of the concrete compressive strength as a function of the 28 days strength

Ages covering the period from one to 60 days for concrete mixes are considered. A correction factors related the concrete strength at any age and the 28 days compressive strength are calculated and presented. These coefficients could be used to predict compressive strength for similar concrete mixes at any age. 


\section{CONCLUSIONS}

An experimental investigation to study the efficiency of using single non destructive test and combined test methods to predict the concrete compressive strength has been conducted. Different concrete mixes including different types of coarse aggregates and mix proportions are considered. The concrete strength values were continuously followed by applying RH test, UPV test rather than the crushing strength test. Concrete ages from one day to 60 days were covered. Based on the results and the analysis, the following conclusions could be drawn;

1. With a reasonable correlation coefficient, RH and UPV tests could be implemented individually to measure the compressive strength of concrete at age rang from one to sixty days.

2. The RH method and UPV method appears to be more competent in forecasting the compression strength of concrete.

3. The use of both of the RH and the UPV tests together as a combined method produces more reliable results that are closer to the actual values compared to the use of one of the implemented methods individually. An acceptable level of precision is additionally appreciated for concrete strength estimation. Therefore, the resulting equations for strength prediction could be used securely for in situ concrete strength assessment.

4. A good single variable relation between $R$ and compressive strength $F_{c}$ is proposed (Eq. 10). This equation is capable of predicting the compressive strength with correlation coefficient approaches $\mathrm{R}^{2}=$ 0.9307 .

5. A good single variable relation between $\mathrm{V}$ and compressive strength $F_{c}$ is proposed (Eq. 11). The proposed equation is capable of predicting the compressive strength with correlation coefficient approaches $\mathrm{R}^{2}=0.9946$.

6. A good multi variable relation between $\mathrm{R}$ and $\mathrm{V}$ against compressive strength $\mathrm{F}_{\mathrm{c}}$ (Eq. 12 ) is proposed. The proposed equation is capable of predicting the compressive strength with higher correlation coefficient.

7. A useful equation with a correlation coefficient $\mathrm{R}^{2}=0.9928$ could be used to predict the strength of the corresponding concrete mixes based on the concrete compressive strength at a given age.

\section{REFERENCES}

[1] Kurtulus C., Bozkurt A., Determination of Concrete Compressive Strength of the Structures in Istanbul and Izmit Cities (Turkey) by Combination of Destructive and Non-Destructive Methods, International Journal of the Physical Sciences Vol. 6 (16), 18 August 2011, pp. 3929-3932.

[2] INTERNATIONAL ATOMIC ENERGY AGENCY IAEA, Guidebook on Non-Destructive Testing of Concrete Structures, TRAINING COURSE SERIES No. 17, VIENNA, 2002.

[3] ACI Manual of Concrete Practice, In-Place Methods to Estimate Concrete Strength, ACI 228.1R-03, MCP 2008.

[4] ACI Manual of Concrete Practice, Nondestructive Test Methods for Evaluation of Concrete in Structures, ACI 228.2R-98, MCP 2008.

[5] Kesler C.E., Higuchi Y., Determination of Compressive Strength of Concrete by Using its Sonic Properties, Proc. ASTM, 53, 1044, 1953.

[6] Skramtaev B.G., Leshchinsky M.Yu., Complex Methods for Non-Destructive Tests of Concrete in Constructions and Structural Works, RILEM Bull., Paris, New Series No. 30 March (1966) 99.

[7] Wiebenga J.G., A Comparison between Various Combined Non-Destructive Testing Methods to Derive the Compressive Strength of Concrete, Rep. kB1-68-61/1418, Inst. TNO Veor Bouwmaterialen en Bouwconstructies, Delft, the Netherlands, 1968.

[8] Samarin A., Smorchevsky G., The NonDestructive Testing of Concrete, Central Research Laboratory, Internal Tech. Rep. No. 54, 1973.

[9] Meynink P., Samarin A., Assessment of Compressive Strength of Concrete by Cylinders, Cores and Non-Destructive Tests, RILEM Symp., in: Proc. on Quality Control of Concrete Structures, Session 2.1, Swedish Concrete Research Institute Stockholm, Sweden, 1979, pp. 127-134.

[10] Tanigawa Y., Baba K., Mori H., Estimation of Concrete Strength by Combined Non Destructive Testing Method, ACI SP- 82, 1984, pp. 57-76.

[11] Kheder G.F., A Two Stage Procedure for Assessment of In-Situ Concrete Strength Using Combined Non-Destructive Testing, Mat. Structures 32, 1998, pp. 410-417.

[12] Qasrawi Y.H., Concrete Strength by Combined Nondestructive Methods Simply and Reliably Predicted, Cement and Concrete Res., 30, 2000, pp.739-746.

[13] Shariati M. et al., Assessing the Strength of Reinforced Concrete Structures Through Ultrasonic Pulse Velocity and Schmidt Rebound Hammer Tests, Scientific Research and Essays, Vol. 6 (1), 4 January 2011, pp. 213-220. 
[14] Erdal M., Prediction of the Compressive Strength of Vacuum Processed Concretes Using Artificial Neural Network and Regression Techniques, Vol. 4 (10), October 2009, pp. 10571065.

[15] ACI SP-144, Concrete Technology-Past, Present and Future, P.K. Mehta, Ed, American Concrete Institute, Detroit, MI, 1994, pp. 623-678.

[16] Egyptian Code ECP:203 (2007), Egyptian Code for Design and Construction of Reinforced Concrete Structures, Annual Book for Testing of materials, Part 3, Ministry of Housing and Urbanization, Housing and Building Research
Center, Cairo, Egypt.

[17] BS 1881: PART 103 (1993), Method for Determination of Compacting Factor.

[18] BS 1881: PART 108 (1983), Method for Making Test Cubes from Fresh Concrete.

[19] BS 1881: PART 115, Testing ConcreteSpecification for Compressive Testing Machine of Concrete.

[20] Yaman I.O., G.I., Yesiller N., Aktan H.M., Ultrasonic Pulse Velocity in Concrete Using Direct and Indirect Transmission, ACI Material Journal, Nov.-Dec. 2001, pp. 450-457. 